\title{
GROUP MODEL BUILDING WITH CAUSAL LOOP DIAGRAMS TO FOSTER CAPABILITIES FOR SUSTAINABLE DESIGN AND PRODUCT DEVELOPMENT
}

\author{
M. Watz ${ }^{\otimes}$ and S. I. Hallstedt \\ Blekinge Institute of Technology, Sweden \\ $\triangle$ matilda.watz@bth.se
}

\begin{abstract}
This research proposes a group model building workshop method that uses causal loop diagrams to foster capabilities for sustainable product development based on feedback and observations from several cases. The method's potential to enhance sustainability system thinking skills and to identify relationships between sustainability criteria and traditionally identified requirements is evaluated. The method can trigger discussion, visualize complexity and dependencies of sustainable design problems. Other application areas are e.g., sustainability training for practicing engineers and students.
\end{abstract}

Keywords: sustainable design, complexity, design methods, group model building, causal loop diagrams

\section{Introduction}

Organisational sustainability capabilities are key for successful implementation of support methods and tools for sustainable design and product development (Brones et al., 2014). Although systematic efforts are important constituents of these capabilities, such as implementation of tools and methods, 'soft' aspects are too. Decision-making that leads to minimised unintended negative socio-ecological consequences, requires shared mental models of the desired goal situation, as well as the current, and the factors that can influence the situation towards the desired state (Waage, 2007; Mendoza et al., 2017). Previous studies have furthermore showed, that even though a sustainability strategy have been systematically implemented in the operational management system, it does not necessarily mean that the scope of this strategy adopts a socio-ecological systems perspective (Ceschin and Gaziliusoy, 2016). The socio-ecological criteria that is brought into the product innovation process may then fail to be contextually relevant for the company and will hence not be prioritised in trade-offs with other requirements. One way for socio-ecological considerations to become a part of the design rationale, is to quantify sustainability performance and integrate this data in traditional engineering design model environments. For example, tools based on traditional design methods, e.g., Quality Function Deployment (QFD), Design Structure Matrix (DSM), Theory of Inventive Solving (TRIZ), etc. that are combined with ecodesign tools do not acknowledge the importance of the contextualisation and traceability in the selection of sustainability aspects to integrate (Watz and Hallstedt, 2018). Such tools, however, have a low implementation rate in industry (Held et al., 2018). It seems that methods that can achieve both traceability in the chain of decision-making, organisational commitment and 'soft' sustainability 
capabilities are needed for increased sustainable product development (SPD) implementation in product developing companies, see e.g., (Pigosso et al., 2013; Brones et al., 2014; Gould, 2018)

\subsection{Aim and objectives}

The aim of this paper is to share insights from the development and test application of a novel methodological approach to enhance sustainability systems thinking capabilities in early design decisionmaking processes. The main objective is to explain the scientific background and development of a novel workshop method and its design. The objective is also to share reflections around usability, utility areas and improvements of the method. The research question guiding the design and execution of the study was 'can group model building with causal loop diagrams, foster design team capabilities for sustainable design, and if so how?. The remaining of this paper is structured as follows; section 3 describes the research design and method development, section 4 outlines the results, i.e., a proposed method and outcomes of the analysis. Finally, section 5 discusses the outcomes in relation to the aim and objective and provides conclusions, main contributions and ideas for future research.

\section{Background to the selection of group model building with causal loop diagrams as support for sustainable product development}

As most of the lifecycle sustainability performance of a solution is determined by decisions the early concept development phase of the product innovation process, it is essential to have integrated socioecological design criteria into this phase (Poudelet, 2012). However, systematization without a socioecological system contextualization of a design problem can induce risk for sustainability-sub optimizations, that is, unintended negative consequences in another sustainability dimension, i.e., social, ecological, economic, then was originally optimised for (Byggeth and Hcoschorner, 2006; Hjort and Bagheri, 2006; Laurenti, 2016). Soft organizational and individual capabilities must also be improved for successful SPD implementation, and it has even been discussed whether solely soft skills improvement can be more efficient than systematized efforts, see e.g. Siva et al. (2018). Two recent action research studies suggest that a combination of systematisation and soft organizational capabilities improvement is needed for successful implementation of ecodesign (Brones et al., 2017) respectively SPD (Hallstedt and Nylander, 2019). Both studies conclude that top-down initiatives at strategic and tactical management levels, i.e., design of policies and operational management systems including implementation of ecodesign tools, should be combined with bottom-up approaches at operational management level, such as training in sustainability systems thinking. Lack of skills in socio-ecological systems thinking at operational level does not support prioritization of sustainability aspects in trade-offs during early design phases. Therefore, sustainability considerations beyond regulatory compliance struggle to become 'critical', nor 'essential' constituents of requirement specifications (Nilsson et al., 2018; Watz and Hallstedt, 2020). Against the background that few design methods available today, e.g. above mentioned approached using e.g. QFD, DSM, or TRIZ, adopt socio-ecological systems contextualization of sustainability during the identification and interpretation of needs into requirements, little room is given to explore the interplay between sustainability criteria and traditionally identified requirements.

\subsection{Group model building with causal loop diagrams}

McCardle-Keurentjes et al. (2018) describes how active participation in the construction of a model leads to more trust in it, as it increases the ability to recognize critical information within the model. Active modelling could thus enhance the understanding of a problem structure and to more confidence in decisions based on the co-developed model. Group model building (GMB) is such an approach for cogenerative team learning that leads to better data interpretation, systems understanding and confidence within the individual stakeholders in a group of decision-makers, as well as the groups' satisfaction with the decisions being taken (Rouwette et al., 2011). It is useful for collaborative decision-making in complex systems, as teams co-create and visualise mental models. By doing so, relationships between factors that affect the behaviour of a system, and thus influence the state of the desired situation, can be unveiled. The problem context then co-defined within the team, leading to that different stakeholder 
perspectives and assumptions can be discussed (Andersen et al., 2007). This can help decision-makers identify leverage points, that is, key factors for system optimization. Using causal loop diagrams (CLDs) is especially useful to support GMB when there are uncertainties regarding how different aspects of a system, as in the case of design, affect one-another (McCardle-Keurentjes et al., 2018). As causality is visualised in terms of stock and flows, i.e., quantitative units, it is necessary to be specific in the definition of the modelled relationships, which forces decision-makers to discuss and agree on how things are. This entails that CLD forces assumptions to be explained, especially if stakeholders disagree on a relationship in the diagram. Once detailed system behaviours have been unravelled, they can be 'hidden' in a sublayer of the CLD to simplify the model (Vennix, 1996).

These indicated benefits of GMB are similar to what has been suggested as seven important cognitive concepts for successful ecodesign, i.e., responsibility over actions and outcomes, decision-making skills in complex problem structures, ability to simplify judgements and decisions, that good decisions requires some effort, trust in models and information, cognitive dissonance, and motivation for change behaviour (MacDonald and She, 2015). More recently Gould (2018) concluded that designers' individual capabilities for sustainable design can be supported by, preferably a combination of, formal training and practical experience with interactive problem-solving in a relevant context. More attention has therefore been directed towards the importance of the early, and highly discussion-based, activity in the requirement management process on the concept development- and selection phases of a design project. As CLDs are the pre-steps to system dynamic (SD) models, which traditionally has been used for modelling of business cases, policy-making scenarios, earth-system science, and in health care sciences. For the purpose of sustainable product development, GMB, CLD and SD have so far been used for e.g. ecodesign business case modelling (Rodrigues, 2018), and exploration of policy scenarios which can have positive impact on the development of more sustainable products (Laurenti, 2016). From a SPD perspective, GMB using CLD, could be an opportunity to establish a common understanding of sustainability in the context of a specific design project and a way for designers and engineers to improve their sustainability systems thinking skills (Jaghbeer et al., 2017; Ny, 2009). It is then expected that the use of a systems perspective of lifecycle socio-ecological aspects can be increased already in conceptual design. With the objective of increasing the use of a socio-ecological systems perspective a group model building method is proposed in this paper. In addition, it is explored how GMB and CLD can be utilised in the product innovation process to support integration of sustainability aspects in a holistic and strategic way.

\section{Research design and method development}

Evolutionary prototyping was employed to adopt a 'soft design science' research approach aiming to improve the design process through qualitative methods of working rather than software-based tools (Baskerville et al., 2009). Hence, the workshop method design was continuously modified based on the feedback and observations collected from each session. Running the workshops was hence a method for the researchers to better understand the research problem and gain insights to how it could be addressed. The research study expanded over 1,5 years and the material generated by the participants was continuously collected from each workshop and used together with feedback, memos, and a research diary, all used to refine the workshop method in an evolutionary manner. At the end of the workshop prototyping, all material from the resulting four workshops, i.e., WS1, WS2, WS3 and WS4, was consolidated using qualitative content analysis. Figure 1 shows an overview of the workshop method development process.

\subsection{Participant selection and data collection}

Stratified purposeful sampling (Palinkas et al., 2015) was used to select workshop participants. Participants of the two company-situated workshops, i.e., WS1 and WS3, where selected by a company contact. Participants of the two larger workshops, WS2 and WS4, were part of an open research seminar held with a research partner-, and company consortium, respectively participants of the engineering design conference where the workshop was a part of the programme. All workshop invitations included a short background, purpose, aim and description of the method. Participants were consequently representatives from various product developing companies, engineering consultancies, 
academic research groups and countries, and the workshops were held in different locations and group sizes so that both academic and industrial perspectives could be retrieved.

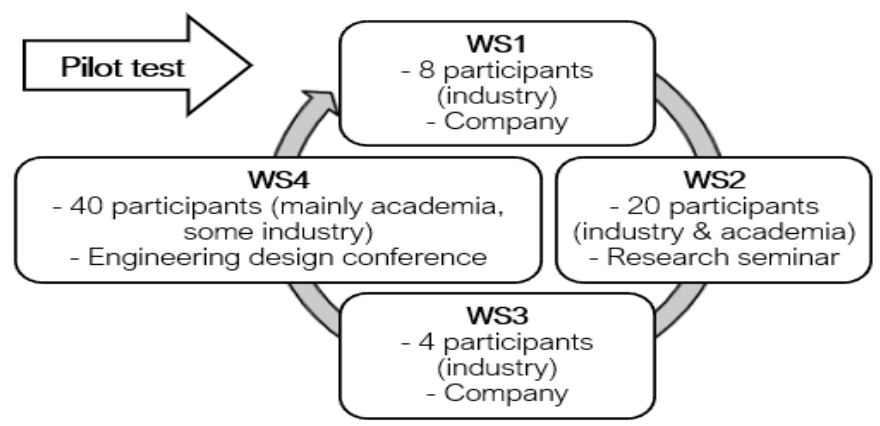

Figure 1. Evolutionary prototyping of workshop development, showing how the workshops were continuously developed using feedback and facilitation experience from previous workshop sessions

\subsection{Evolutionary prototyping process of group model building method}

The workshop approach was first tested in the author's research team which is a team of specialists in the field of sustainable product development research. Based on the discussions at this pilot session, the first workshop session was prepared.

In the first workshop, WS1, which was held at a company with various internal stakeholders in the design organisation, the participants were introduced the importance of systems thinking when integrating sustainability in design and especially in early requirements management. Thereafter they were introduced group model building using causal loop diagrams (CLDs), after which they were provided with a fictive, but company-tailored, sustainable design problem. Guided by a question, one per team of 3 or four participants, they were asked that through CLD modelling identify trade-offs and correlations between traditional requirements and strategic sustainability criteria. WS1 took in total 2 hours, including introduction, modelling and a final discussion during which the participants filled in the feedback forms. WS2 was held shortly after the first in a larger format, at a research seminar, engaging 20 participants from both industry practitioners and researchers. In this session, all participants worked with the same design problem in teams of 4 to five. The same introduction to the purpose and aim of the method were presented, as well as introduction to CLD. The diagrams, notes and feedback forms were collected also from this workshop. WS3 was held at a company in a small group, four purposefully selected experts from the design organisation. The representatives were a product planner, a product owner, technical specialist and a lifecycle cost specialist. Together they modelled a tailored design problem, guided by the main author which gave them a shorter introduction to CLD modelling than in the two previous workshops. A longer discussion was held in this workshop than in the two previous. At this workshop the participants did not fill in the feedback forms but the discussion, still following the questions in the feedback form, was recorded and the researchers took notes which were verified with the participants afterwards. WS4 was held at a conference in engineering design and engaged around 40 participants that were mainly from academia. The workshop started with an introduction to the background and purpose of the method, and the participants were given a brief lecture about group modelling, sustainable product design and CLDs. For this session, the following three changes were made: i) The participants were not provided with a thorough step-by-step CLD modelling example, ii) The participants were however suggested to use reference behaviour diagrams (RBDs), i.e., twodimensional graphs where the qualitatively estimated relationship between two variable in the system is illustrated, see Figure 2, which were explained in the introduction, and iii) A template including a fictive design problem scenario description, with customer requirements and strategic sustainability criteria indicators, and instructions to the CLD modelling was developed and distributed to the participants, which formed teams of four to five. Approximately 2,5 hours were spent on WS2, WS3 and WS4 each which included the same steps as WS1. At all workshops, strategic sustainability criteria, i.e., criteria that are tailored for a company so that they cover both long term- and short term sustainability targets, 
derived from a socio-ecological systems perspective (Hallstedt, 2017), were used in the design problem. In this way, they were contextually relevant for the company, a key characteristic for 'good' requirements (Kotonya and Sommerville, 1998).

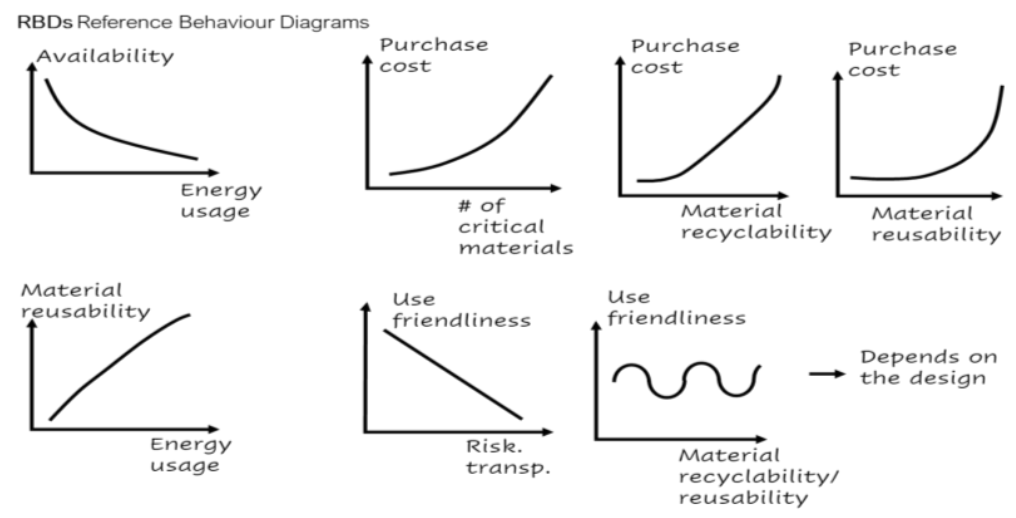

Figure 2. Example of how reference behaviour diagrams were drawn and used in WS4 to discuss relationships between customer requirements and selected sustainability criteria indicators

\subsection{Qualitative content analysis}

To analyse the data collected from the workshop sessions it was decided to apply qualitative content analysis (QCA). A team of four researchers, i.e., two $\mathrm{PhD}$ candidates, a senior researcher and the main author conducted the QCA, which consisted of three main phases. First, a coding frame was established (Schreier, 2012). Thereafter, a joint discussion in four steps, i.e., introduction, opening discussion, open coding, and a final discussion, allowed code categories to emerge inductively drawing upon logic and prior research results described by the main author. The researchers used a combination of colour coding, i.e., one colour per section of the feedback form, and free annotation of key terms and concepts. Finally, the outcome of the coding was discussed, highlighting strong and discrepant themes in each of the three feedback sections. The final step consisted of cross-referencing of all notes and feedback forms and open codes as well as clustering of codes into the highlighted themes. It was annotated whether the participant was a researcher on industry representative to allow comparison of feedback between these categories. Figure 3 gives an overview of the steps that constituted as the QCA process.

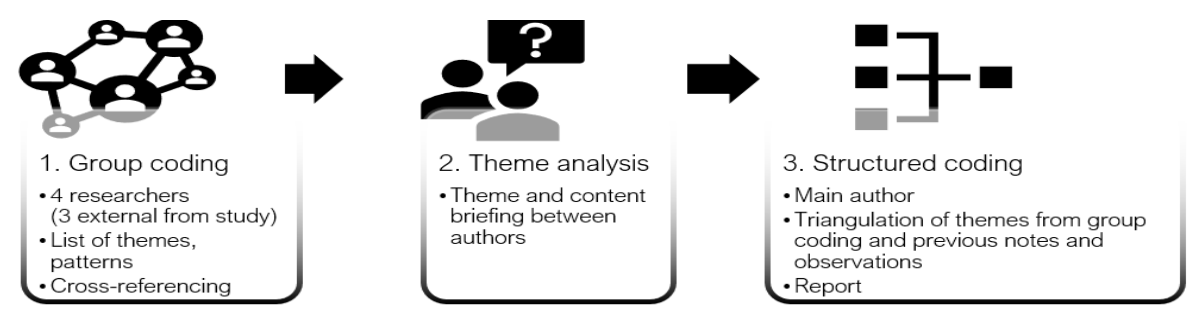

Figure 3. Steps in the qualitative content analysis

\section{Results}

This section describes the results of the evolutionary prototyping and the QAC of collected data.

\subsection{Description of resulting group model building method for sustainable product development}

The workshop started with an introduction to the purpose and aim of the exercise, as well as an introduction to the basics of SPD, GMB and CLD. Thereafter, the participants were divided into teams of four to six that were each provided with a design problem scenario, outlining the main customer requirements (CRs) and leading sustainability criteria indicators (SCI) (Watz and Hallstedt, 2018). Following the steps as indicated by the workshop template, see Figure 4, the teams are asked to i) discuss and mark out which variables they intuitively see relationships between (box ' 3 '), ii) illustrate 
the relationships using RBDs (box '4'), iii) draft a CLD (box ' 5 ') iv) annotate issues that were discussed, such as unravelled variables (box ' 6 '), and v) write down the main findings in box ' 7 '. In total, two hours were allocated for the workshop. The workshop design triggered the teams into discussions around whether, at all, there were links between a designs' performance in relation to ingoing customer needs and sustainability criteria, and if so, if they were causal. To find causality, the team needed to discuss other variables than those provided in the design problem and were in this case asked to annotate them. At the end of the modelling session the aim was that each team should have started to sketch CLD's and annotate new findings, including; sustainability criteria and customer needs that correlated, or trade-offs between them, as well as new insights about key factors outside of the provided scope of variables that came out of the discussion. Figure 5 provides an overview of the sequence of activities, i.e., the main steps, in the developed method.
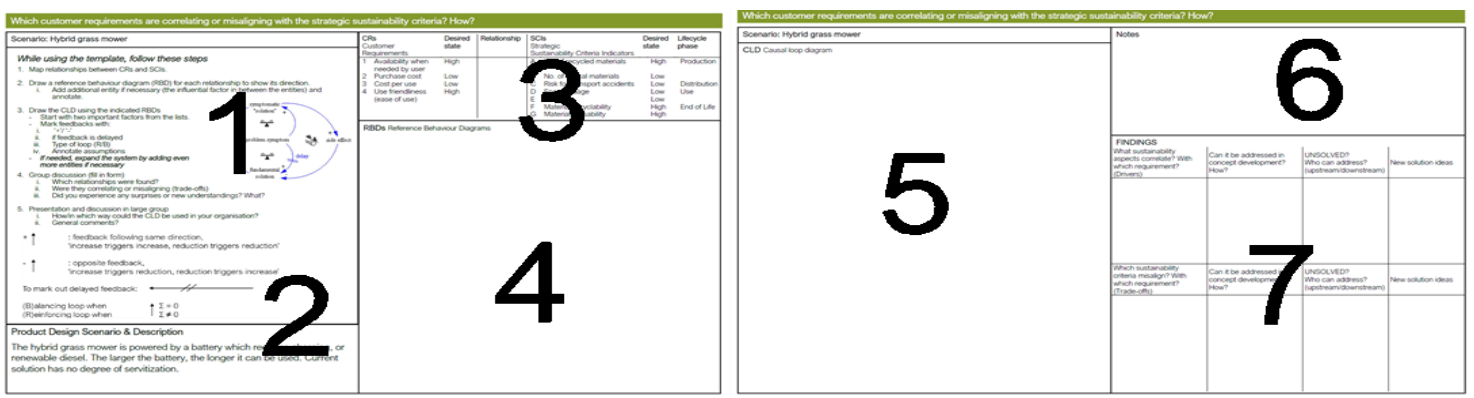

Figure 4. Schematic overview of GMB WS method for SPD templates. Box ' 1 ' provides an instruction to CLD modelling, ' 2 ' gives a brief design scenario description, ' 3 ' gives space to intuitively connect SCls and CRs, ' 4 ' is space to draw RBDs based on links in box ' 3 ', ' 5 ' provides space to sketch a CLD, ' 6 ' is space for free notes, and ' 7 ' is a table where results can be filled in

After the workshop, all participants were provided with feedback forms. The forms were designed according to Design Research Methodology-guidelines for qualitative analysis and support evaluation (Blessing and Chakrabarti, 2009). Participants were asked about prior experience in the methodological approach, their expectations on the session, and about their experience. The three feedback questions were 'Did you experience any surprises or new understandings? What? Which?', 'Could the CLD be used in your organisation? Why/How? For what?', and 'General comments?'. The first two questions aimed to get an indication of the usefulness of the method in relation to its intended purpose, and to room to share ideas of other use areas, whereas the third question gave room for open reflections.

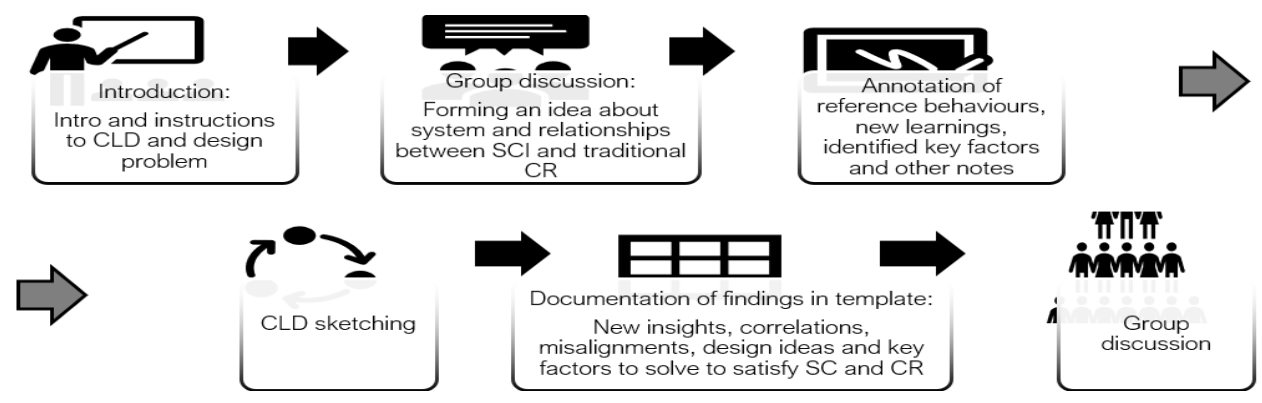

Figure 5. Main steps in GMB method for SPD

\subsection{Results of qualitative content analysis of workshop observations and feedback}

While facilitating, the authors annotated what they observed and heard in the working teams. The CLD's created in the three first workshops were also collected. From the final fourth workshop, all templates were collected. The participants' feedback was collected in addition to the material generated from the modelling exercise. Seven feedback forms were so collected from WS1, 20 were collected from WS2notes and recording from a discussion following the feedback form structure was collected from 
WS3, and from WS4 37 forms were collected. All this this data underwent QCA and resulted in three categories, i) new insights, ii) feedback about usability and application areas, and iii) general comments.

\subsubsection{Participants' new insights}

In the first feedback form category, a total of 75 codes were formed in the inductive coding during the QAC workshop. During the discussion step of this workshop, eight themes emerged which were analysed, and consolidated into six, in the theme analysis step. The six themes were:

i) Importance of system boundaries to complex problems. Some of the participants indicated upon a newfound understanding of system boundaries related to sustainability aspects in design. It was for example mentioned as being interesting to try and build a dynamic problem from static variables and that mapping of system behaviour required a lot of preparation, or detailed knowledge about each of the variables to be analysed in the CLD, ii) Benefit of visualising hidden dependencies. Many participants expressed that they learned or were reminded about the power of visualisation. The method helped some participants to see hidden dependencies between not only sustainability criteria and traditionally identified customer needs, but also between different sustainability criteria and different customer needs, iii) Participants did not learn anything new. Some participants expressed that they did not learn anything new from the method or that they expected the session with its' outcomes to be like it was, iv) Difficult to start. Several participants described that it was difficult to start the exercise with the provided instructions and material. They were not expecting it to be so difficult to start working with a system mapping exercise in a group, $v$ ) A learning by doing approach. There were comments expressing that they found the session being a learning by doing exercise. In this case, the act of modelling itself helped the participant to develop new awareness of a designs' performance in other areas than they traditionally focused on, vi) A quick and easy way to get a systems overview. Some participants saw this method as a fast way to get an overview of the important design aspects that impact the sustainability performance of a product lifecycle. Comments indicate that participants were experiencing an approach to identify relevant variables to include in models for design decision-making.

\subsubsection{Participants' feedback about usability and application areas}

The inductive coding gave rise to a total of 63 codes, from which 20 themes emerged in the "usability and application areas'-category. After the theme analysis, the 20 themes were consolidated into five categories, namely:

i) Design or innovation tool. Comments stated that the method could be used as a tool to stimulate innovation or new solution ideas, as it helped contextualize sustainability within the frame of customer needs. The method could also help designers gain a deeper understanding of the customer needs, in general, ii) Strategic planning tool. Some participants were critical to the usability of the method in the conceptual design but saw other potential application areas, such as business planning for circular business models, value chain design or policy design, iii) Method for pre-studies to design projects. Another category of comments mentioned that the method could be used in pre-studies for design projects. It could be used for high level sustainability assessments and help conduct initial system analysis. Hence, it could visualize performance and sustainability dependencies and perhaps help identify functional conflicts and side effects, iv) A discussion tool. A general comment was that the method was useful to stimulate discussions, at all organizational levels, v) Potential as teaching tool. Many participants saw a strong educative potential in the method. Comments mentioned that it could be used both in organizations and in engineering education to enhance sustainability systems thinking skills. More specifically, it could be used both as a 'introduction to sustainability' tool, or as a sustainable design education method in either university programs or at design and manufacturing companies.

\subsubsection{Participants' general comments}

From a total of 61 inductively created codes created during the QAC workshop, fourteen themes emerged in the 'general comments' category. These were thereafter abstracted into six larger categories in the theme analysis step. The resulting themes within the general comments were:

i) The purpose of the method was unclear. Some participants expressed that they did not see the added value of this method in comparison to other decision support tools for engineering design, such as the 
design structure matrix or failure models and effects analysis. Other comments expressed the need for an example in the introduction of the workshop to better understand how to perform the exercise and how to use the results. Some participants mentioned that a simpler exercise with fewer variables would have been easier, since they claimed that the modelling required detailed data, ii) A means to understand and discuss complexity. Many participants described that the method was an eye-opener for complexity and that they were reminded of how many factors that influence the performance of a design. Some participants mentioned that the method was useful to initiate discussion about sustainability that otherwise would not occur and that it could be useful to have structured discussions for other aspects than sustainability only, iii) A positive experience. Although many participants commented on the need for more contextualisation to understand the purpose and value of the method, several comments expressed a positive experience. These included the facilitation of the exercise itself and appreciation for a novel approach in the field of sustainable design, iv) Digitalisation opportunities and new business ideas. Some general comments said that the method gave rise to innovative ideas for digitalisation and new business models. For instance, the system mapping could help identify which sustainability parameters to include in a digital model to improve the accuracy of performance evaluation in the concept generation and evaluation phase from a sustainability perspective. Other comments involved statements such as 'triggers marketing thoughts', indicating that the method helped identify design improvement aspects to be issued to upstream functions of the organisation, such as the marketing department, by designers at operational management level, v) Improvement suggestions. Many of the general comments included clear improvement suggestions, besides the request for examples in the introduction for contextualisation, on both the facilitation and on the workshop material. These involved e.g. using a refined and consistent wording of terms and constructs, and to add a box to the template that explained the concept of systems thinking.

\section{Concluding discussion}

This paper has described the research process from which a group model building method, based on causal loop diagramming, was developed, aiming to enhance capabilities for sustainability systems thinking in early phases of engineering design projects. The main steps of the method are: Problem description, discussion of relationships between customer requirements and leading sustainability criteria indicators, identification of additional design variables and co-generation of a CLD, annotation of new insights and discoveries, and annotation of found correlations or trade-offs between sustainability criteria and traditionally identified requirements. The method was prototyped by the team during 1,5 years during which four workshops were held, allowing the method to be refined continuously during the research study. GMB based on CLD was selected due to its potential to foster soft capabilities for SPD, as well as providing a basis for quantitative dynamic modelling to be integrated in an engineering environment. By using a pre-defined problem definition, constituting of a set of variables and a question that triggered systems thinking, participants went through a CLD modelling phase where new variables could be identified and the relative importance of the variables in relation to the problem definition were discussed and illustrated. The exercise aimed to help participants visualise the otherwise ambiguous sustainability impacts of design decisions, which often are delayed. Although delayed feedback can be marked out in CLDs using specific symbols, it was decided not to do so, as most sustainability impacts are delayed from a product life management perspective (Ulrich and Eppinger, 2012; Laurenti et al., 2014). The methodological design allowed the researchers to gain better understanding of how of group model building, facilitated by a qualitative tool such as CLD can be used to foster soft capabilities for SPD.

\subsection{Usability, applicability and limitations of developed method}

Based on the QCA it was possible to distinguish themes of applicability, usability and limitations for the developed GMB workshop method. Firstly, the method gave rise to new insights among the participants which followed six themes, i.e., a strengthened appreciation of system boundaries in relation to complex problem-solving, a benefit in visualisation to reveal hidden dependencies, that group model building using causal systems thinking is a learning by doing approach, and that the developed method can be used to in a quick and easy way to get an overview of a systems problem. However, some participant 
stated that the method did not teach them anything new and that it was difficult to start, indicating that the workshop should be assigned more time and facilitation. Secondly, feedback indicated that the method can be used as a design or innovation tool, because it supported a deepened understanding both sustainability in the context of the customer need profile and dependencies between stakeholder needs in general. Other use and application areas were strategic planning in terms of business-, value chain-, and policy planning, and to be used in pre-studies for design and innovation projects. Finally, participants saw potential in the method for applications in education and sustainability training, or as a general discussion tool to be used at all organisational levels. Thirdly, participants gave general comments about the method which followed five themes, i.e., that the purpose of the method was unclear, that the method was a means to gain understanding about complexity, that they liked the experience of testing the method, that the method gave rise to new business ideas and digitalisation opportunities, and suggestions for improvements. A general limitation is that the QCA did not analyse the participants' experiences related to their prior knowledge about GMB, CLD, or SPD. However, this limitation can reflect a real life situation if the method was used in e.g. an industrial design team.

\subsection{Concluding remarks and outlook}

The insights mentioned in the previous section have given rise to ideas for future improvements and applications of the method. For instance, the results indicated that the method can be used in several settings besides the intended situation, i.e., early requirement discussions for product innovation projects. One of the general reflections was that the purpose of the method was unclear, why improvement ideas, e.g. prolonged modelling time and enhanced contextualisation, and suggestions for other use areas will be used to further refine the method and test it for verification. For instance, a next iteration will be conducted at a case company, in an action research study, with a real design problem while using more time and detailed data. Then, it can be investigated if the resulting model can be computerised and integrated in a digital design environment and support decision-making. This may be interesting as GMB helps visualize dependencies between stakeholder values in design problems. It can further be explored if and how the resulting model and generated insights can be captured and used in the design rationale, i.e., the documentation providing the traceability of requirements in an engineering design project (Poorkiany, 2017). The GMB method can also be tested in education and as part of a sustainable design training programme to enhance SPD capabilities of future and current engineers.

\section{References}

Andersen, D.F. et al. (2007), "Group model building: problem structuring, policy simulation and decision support”, Journal of the Operational Research Society, Vol. 58 No. 5, pp. 691-694. https://doi.org/10.1057/ palgrave.jors.2602339

Baskerville, R., Pries-Heje, J. and Venable, J. (2009), "Soft design science methodology", In Proceedings of the 4th Int. Conference on Design Science Research in Information Systems and Technology, pp. 1-11. https:// doi.org/10.1145/1555619.1555631

Blessing, L.T. and Chakrabarti, A. (2009), DRM: A design reseach methodology, Springer, London, pp. 13-42. https://doi.org/10.1007/978-1-84882-587-1_2

Brones, F., de Carvalho, M.M. and de Senzi Zancul, E. (2014), "Ecodesign in project management: a missing link for the integration of sustainability in product development?", Journal of Cleaner Production (JLCP), Vol. 80, pp. 106-118. https://doi.org/10.1016/j.jclepro.2014.05.088

Brones, F.A., de Carvalho, M.M. and de Senzi Zancul, E. (2017), "Reviews, action and learning on change management for ecodesign transition”, JLCP, Vol. 142, pp. 8-22. https://doi.org/10.1016/j.jclepro.2016.09.009

Byggeth, S. and Hochschorner, E. (2006), "Handling trade-offs in ecodesign tools for sustainable product development and procurement”, JLCP, Vol. 14 No. 15-16, pp. 1420-1430. https://doi.org/10.1016/j.jclepro.2005.03.024

Ceschin, F. and Gaziulusoy, I. (2016), "Evolution of design for sustainability: From product design to design for system innovations and transitions", Design studies, Vol. 47, pp. 118-163. https://doi.org/10.1016/ j.destud.2016.09.002

Gould, R. (2018), The individual human side of supporting sustainable design beginners [Doctoral dissertation], Blekinge Institute of Technology. ISBN: 9789172953574

Hallstedt, S.I. (2017), "Sustainability criteria and sustainability compliance index for decision support in product development”, JLCP, Elsevier Ltd, Vol. 140, pp. 251-266. https://doi.org/10.1016/j.jclepro.2015.06.068 
Hallstedt, S.I. and Nylander, J.W. (2019), "Sustainability research implementation in product developmentlearnings from a longitudinal study", In Proceedings of the Design Society: Int. Conference on Engineering Design, Delft, The Netherlands, August, 2019, Cambridge University Press, pp. 3381-3390.

Held, M. et al. (2018), "Current challenges for sustainable product development in the German automotive sector: A survey based status assessment”, JLCP, Vol. 195, pp. 869-889. https://doi.org/10.1016/j.jclepro.2018.05.118

Hjorth, P. and Bagheri, A. (2006), "Navigating towards sustainable development: A system dynamics approach", Futures, Vol. 38 No. 1, pp. 74-92. https://doi.org/10.1016/j.futures.2005.04.005

Jaghbeer, Y. et al. (2017), "Exploration of simulation-driven support tools for sustainable product development", Procedia CIRP, Vol. 64, pp. 271-276.

Kotonya, G. and Sommerville, I. (1998), Requirements engineering: processes and techniques, Wiley Publishing, ISBN: 04719720889780471972082.

Laurenti, R. et al. (2014), "Group Model-Building to identify potential sources of environmental impacts outside the scope of LCA studies”, JLCP, Vol. 72, pp. 96-109. https://doi.org/10.1016/j.jclepro.2014.03.001

Laurenti, R. (2016), The karma of products: Exploring the causality of environmental pressure with causal loop diagram and environmental footprint [Doctoral dissertation], KTH Royal Institute of Technology. ISBN: 9789175959108

MacDonald, E.F. and She, J. (2015), "Seven cognitive concepts for successful eco-design”, JLCP, Vol. 92, pp. 23-36. https://doi.org/10.1016/j.jclepro.2014.12.096

McCardle-Keurentjes, M.H. et al. (2018), "Potential benefits of model use in group model building: insights from an experimental investigation", System Dynamics Review, Vol. 34 No. 1-2, pp. 354-384. https://doi. org/10.1002/sdr.1603

Mendoza, J.M.F. et al. (2017), "Integrating Backcasting and Eco-Design for the Circular Economy: The BECE Framework", Journal of Industrial Ecology, Vol. 21 No. 3, pp. 526-544. https://doi.org/10.1111/jiec.12590

Nilsson, S., Sundin, E. and Lindahl, M. (2018), "Integrated product service offerings-Challenges in setting requirements", JLCP, Vol. 201, pp. 879-887. https://doi.org/10.1016/j.jclepro.2018.08.090

Ny, H. (2009), Strategic life-cycle modeling and simulation for sustainable product innovation [Doctoral dissertation], Blekinge Institute of Technology. ISBN: 9789172951655

Palinkas, L.A. et al. (2015), "Purposeful sampling for qualitative data collection and analysis in mixed method implementation research", Administration and Policy in Mental Health and Mental Health Services Research, Vol. 42 No. 5, pp. 533-544. https://doi.org/10.1007/s10488-013-0528-y

Pigosso, D.C., Rozenfeld, H. and McAloone, T.C. (2013), "Ecodesign maturity model: a management framework to support ecodesign implementation into manufacturing companies”, JLCP, Vol. 59, pp. 160173. https://doi.org/10.1016/j.jclepro.2013.06.040

Poorkiany, M. (2017), Managing design rationale in the development of product families and related design automation systems [Doctoral dissertation], Jönköping University, School of Engineering. ISBN: 9789187289323

Poudelet, V. et al. (2012), "A process-based approach to operationalize life cycle assessment through the development of an eco-design decision-support system", JLCP, Vol. 33, pp. 192-201. https://doi.org/ 10.1016/j.jclepro.2012.04.005

Rodrigues, V.P. (2018), “In search of gold”: measuring performance and evaluating potential business benefits of ecodesign, [Doctoral dissertation], DCAMM Report, no. S252, Technical University of Denmark, Department of Mechanical Engineering.

Rouwette, E.A. et al. (2011), "Modeling as persuasion: the impact of group model building on attitudes and behavior", System Dynamics Review, Vol. 27 No. 1, pp. 1-21. https://doi.org/10.1002/sdr.441

Schreier, M. (2012), Qualitative content analysis in practice, SAGE, London; Los Angeles. https://doi.org/10. 1075/ssol.3.1.15aaf, [Calif.].

Siva, V., Gremyr, I. and Halldórsson, Á. (2018), “Organising Sustainability Competencies through Quality Management: Integration or Specialisation”, Sustainability, Vol. 10 No. 5, p. 1326. https://doi.org/10.3390/ su10051326

Ulrich, K.T. and Eppinger, S.D. (2012), Product design and development (5., Int. ed.). McGraw-Hill/Irwin, Boston, Mass. ISBN: 9780071086950

Vennix, J.A.M. (1996), Group model building: facilitating team learning using system dynamics, Wiley, Chichester.

Waage, S.A. (2007), "Re-considering product design: a practical 'road-map' for integration of sustainability issues", JLCP, Vol. 15 No. 7, pp. 638-649. https://doi.org/10.1016/j.jclepro.2005.11.026

Watz, M. and Hallstedt, S.I. (2018), "Integrating Sustainability in Product Requirements", In DS92: Proceedings of the DESIGN 2018 15th Int. Design Conference, Dubrovnik, Croatia, May 2018, pp. 1405-1416. https:// doi.org/10.21278/idc.2018.0377

Watz, M. and Hallstedt, S.I. (2020), "Profile model for management of sustainability integration in engineering design requirements", JLCP, Vol. 247, p. 119155. https://doi.org/10.1016/j.jclepro.2019.119155 